\section{Alpha Rhythms in the Hyperkinetic Child}

HYPERKINESIS is a poorly understood but common disorder of childhood the main features of which are excessive motor activity, a short span of attention, low tolerance of frustration and hyperexcitability, often resulting in learning difficulties and a poor motor performance even where intelligence is normal. The neurophysiological substrate of this disorder remains undefined and emotional factors have often been invoked as its sole basis. Some children with this syndrome improve when given central nervous system stimulant drugs; We have attempted to distinguish those children who are likely to improve from those who may not.

The reaction times of human subjects are shorter when the signal to respond is given during spontaneous beta waves than when it is given during spontaneous alpha waves ${ }^{1}$. Beta waves seem to represent a process of cortical excitation, such that they appear when stimuli are perceived as novel and disappear with habituation ${ }^{2-4}$. Alpha rhythms are said to represent an inhibitory process involving discharge of subcortical influences back into the cortex, and effecting the termination of cortical excitation associated with automatization or habituation of learned behaviour ${ }^{2}$.

Alpha rhythms were therefore studied in a group of hyperkinetic children as a possible measure of increased attention span. Twenty-eight children between the ages of 5 and 12, recognized by history and examination to have hyperkinesis and decreased attention span without psychomotor retardation, were chosen. Subjective scoring by parents and school teachers and objective measurements of activity level, impulsivity, performance and coordination were obtained for each child at the beginning of the study. Intravenous dextroamphetamine (10 $\mathrm{mg} \mathrm{m}^{-2}$ body surface area), methylphenidate $\left(20 \mathrm{mg} \mathrm{m}^{-2}\right.$ body surface area), or saline in equivalent volume was injected in random order, using double blind methods, into these twenty-eight children during an electroencephalographic (EEG) examination. The EEG responses were collected on magnetic tape $15 \mathrm{~min}$ before and $15 \mathrm{~min}$ after the injection, for $3 \mathrm{~min}$ each. Five control subjects were injected with one of the stimulant drugs (four had dextroamphetamine and one had methylphenidate), and their EEG responses were similarly recorded on magnetic tape. Silver electrodes were applied using the International 10-20 System and the eyes of the subjects were kept open throughout the experiment ${ }^{5}$. The potentials between $\mathrm{P}_{4}$ and $\mathrm{O}_{2}$ were analysed. A PDP-12 computer was used for the data analysis. The computer sampled four $17 \mathrm{~s}$ segments each from pre-injection and post-injection periods and performed the Cooley-Tukey fast Fourier transformation. The statistical test used the mean power of these four segments for pre-injection and post-injection periods.

Each of these children was put on oral therapy with dextroamphetamine, methylphenidate, or a placebo in random order, using double blind methods. Repeat subjective scoring and objective measurements of activity level, impulsivity, performance, and coordination were obtained at the end of a 3-week period. At that time all the subjects of the study were put on oral therapy with one of the central nervous system stimulant drugs (dextroamphetamine or methylphenidate) and followed during the next $2 \mathrm{yr}$.

Table 1 shows the correlations between response to oral therapy with central nervous stimulant drugs and the response of EEG alpha rhythms to the intravenous injection of these drugs. The final results are expressed by a ratio $r$, where $r=$

EEG power alpha range ( 8 to $12 \mathrm{~Hz}$ ) in the post-injection period EEG power in alpha range $(8$ to $12 \mathrm{~Hz})$ in the pre-injection period

The results generally show an increase in alpha activity in those who responded well to oral drug therapy but not in those who did not. The Mann-Whitney $U$ test was used to examine the difference between these two groups, which differed significantly $(P<0.05)$. The control subjects injected with one of the central nervous stimulant drugs showed a consistent increase in alpha activity.

A retrospective analysis of the clinical effects noted immediately after injection of one of the drugs showed that those children who had a poor response to the oral therapy on followup had all shown a remarkable amount of restlessness, talkativeness, and inability to sleep.

\begin{tabular}{|c|c|c|c|c|}
\hline \multirow[t]{2}{*}{ Table 1} & Response o & \multicolumn{2}{|c|}{$\begin{array}{l}\text { Hyperkinetic Children to } \\
\text { System Stimulants }\end{array}$} & \multirow{2}{*}{$\begin{array}{c}\text { ntral Nervous } \\
\text { Saline } \\
\text { injection }\end{array}$} \\
\hline & & Drug injection & & \\
\hline \multicolumn{5}{|c|}{ Hyperactive children } \\
\hline & $\begin{array}{l}\text { Good } \\
\text { response to } \\
\text { the treatment }\end{array}$ & $\begin{array}{l}\text { Poor } \\
\text { response to } \\
\text { the treatment }\end{array}$ & $\begin{array}{l}\text { Normal } \\
\text { controls }\end{array}$ & $\begin{array}{l}\text { Hyperactive } \\
\text { children }\end{array}$ \\
\hline 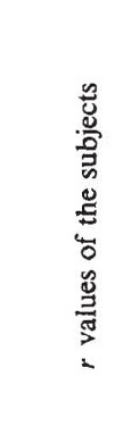 & $\begin{array}{r}28.85 \\
8.20 \\
6.60 \\
5.13 \\
3.66 \\
1.85 \\
1.61 \\
1.49 \\
1.32 \\
0.76 \\
0.74 \\
0.49 \\
0.48 \\
0.40 \\
0.37\end{array}$ & $\begin{array}{l}1.54 \\
0.68 \\
0.43 \\
0.42 \\
0.40 \\
0.13\end{array}$ & $\begin{array}{l}6.16 \\
2.77 \\
1.86 \\
1.45 \\
1.36\end{array}$ & $\begin{array}{l}2.33 \\
1.27 \\
0.98 \\
0.98 \\
0.81 \\
0.78 \\
0.55\end{array}$ \\
\hline
\end{tabular}

The basic neurophysiological defect in hyperkinesis of childhood seems to be a disorder of inhibitory mechanisms in the central nervous system such that irrelevant stimuli are not filtered out and the child is at the mercy of all the stimuli in his environment. Central nervous stimulant drugs seem to be able to activate or strengthen these inhibitory mechanisms. If alpha rhythm in the EEG is an index of relaxed wakefulness, habituation to a class of stimuli, should result in augmentation of alpha. The increase in alpha rhythms seen in those who responded well to the drugs supports this hypothesis.

This work was done while I was a research fellow in neurology at the Harvard University Medical School in Boston.

\section{TaRanath ShetTy}

Division of Pediatric Neurology,

Boston City Hospital,

Boston,

Massachusetts 02118

Received June 21; revised August 2, 1971.

${ }^{1}$ Dustman, R. E., Boswell, R. S., and Porter, P. B., Science, 137, $533(1962)$

2 Darrow, C. W., Veith, R. N., and Wilson, J., Science, 126, 74 (1957).

${ }^{3}$ Sokolov, E. N., Ann. Rev. Physiol., 25, 545 (1963).

4 Mulholland, T., and Davis, E., Science, 152, 1104 (1966).

5 Mulholland, T., Nature, 206, 746 (1965).

\section{Loss of the Sensory Process of an Insect Receptor at Ecdysis}

CAMPANIFORM sensilla on cockroach legs are mechanosensitive sense organs associated with the exoskeleton which are thought to help coordinate the animal's walking movements ${ }^{1}$. Although the fine structure of campaniform sensilla has been elucidated ${ }^{2}$, 